\title{
STRATEGI PEMASARAN PRODUK HERBALIFE (STUDI KASUS RUMAH NUTRISI GREEN)
}

\author{
Gleyni Supit \\ Ribka M. Kumaat \\ Agnes E. Loho
}

\begin{abstract}
This study aims to determine the marketing strategy Herbalife in Manado City. The method of determining the area of research done in purposive, using the case study method which is a description of a real-life experience, which is used to make points, raise issues or otherwise enhance understanding and learning experience of the participants. Where, Nutrition Green House as a location or point of research. Data analysis method used is descriptive analysis, SWOT analysis, and business strategy theory. The results showed that the strategies that have been applied are maintained and add to the marketing strategy of "investment strategy", which prioritizes the development of this strategy over the larger business. Home Nutrition Green brings their positive impact on the communities that exist around the city of Manado. Its positive impact, among other things, the public can find out how to live healthy by consuming Herbalife products with the benefits contained in any product without considering the price of Herbalife products.
\end{abstract}

Keywords: marketing strategy, Herbalife Products, Nutrition Green House, Manado City

\begin{abstract}
ABSTRAK
Penelitian ini bertujuan untuk menentukan strategi pemasaran herbalife di Manado. Metode penentuan daerah penelitian dilakukan secara puposive, dengan menggunakan metode studi kasus yaitu merupakan deskripsi mengenai suatu pengalaman dalam kehidupan nyata, yang digunakan untuk menetapkan poin-poin penting, memunculkan masalah atau bahkan meningkatkan pemahaman dan pengalaman belajar dari para peserta. Dimana, Rumah Nutrisi Green sebagai lokasi atau tempat penelitian. Metode analisis data yang digunakan adalah analisis deskriptif, analisis SWOT, dan teori strategi bisnis. Hasil penelitian menunjukkan bahwa strategi yang telah diterapkan tetap dipertahankan dan menambah strategi pemasarannya yaitu "strategi investasi", dimana strategi ini lebih mengutamakan perkembangan usaha yang lebih besar. Adanya Rumah Nutrisi Green membawa dampak positif bagi masyarakat yang ada disekitar Kota Manado. Dampak positifnya, antara lain, masyarakat dapat mengetahui cara hidup sehat dengan mengkonsumsi produk herbalife dengan manfaat yang terkandung dalam setiap produk tanpa mempertimbangkan harga dari produk herbalife.
\end{abstract}

Kata kunci: strategi pemasaran, Produk Herbalife, Rumah Nutrisi Green, Kota Manado

\section{PENDAHULUAN}

\section{Latar Belakang}

Kesehatan merupakan kata yang sangat sulit untuk didefinisikan, tetapi kesehatan sangat penting dalam kehidupan kita. Sehingga banyak upaya kita manusia untuk menjaga kesehatan. Kesadaran masyarakat terhadap kesehatan masih sangat rendah. Kesehatan masyarakat merupakan suatu bentuk upaya pemerintah dan masyarakat untuk menerapkan gaya hidup sehat untuk masyarakat. Sebab rendahnya kesadaran masyarakat akan pentingnya kesehatan masih nampak terlihat dalam kehidupan sehari-hari.

Untuk itulah ada banyak cara dilakukan untuk memperoleh kesehatan, seperti dengan mengkonsumsi herbalife. Produk herbalife ini sangat berguna untuk menjaga kesehatan kita.

Herbalife adalah Sebuah perusahaan kelas dunia dengan kantor pusat di USA dengan 
produk produk makanan nutrisi untuk kesehatan Anda. Herbalife didirikan atas dasar cinta kasih seorang anak bernama Mark Hughes kepada Ibunya yang seorang aktris Hollywood yang meninggal akibat overdosis obat pelangsing demi mendapatkan tubuh yang ideal.Sudah 17 tahun ini herbalife dipimpin oleh CEO kelas dunia bernama Michael O Johnson yang lama bergelut di Walt Disney, membuat perusahaan ini berkembang pesat dengan kenaiakan setiap tahunnya.

Pada tahun 2000 produk herbalife masuk ke pasar di Indonesia tepatnya di Jakarta dan pada tahun 2001 produk herbalife ini masuk ke Manado. Produk-produk herbalife tersebut terbuat dari bahan-bahan hasil pertanian seperti coklat, strawberry, lidah buaya, teh yang sudah mengalami proses industri yang telah teruji di lebih dari 78 negara, Bahkan produk utama herbalife telah ada sejak lebih dari 30 tahun yang lalu.

\section{Rumusan Masalah}

1. Bagaimana pemasaran herbalife di Kota Manado?

2. Bagaimana strategi pemasaran herbalife?

\section{Tujuan Penelitian}

Penelitian ini bertujuan untuk menentukan strategi pemasaran herbalife di Kota Manado.

\section{Manfaat Penelitian}

Berdasarkan hasil penelitian ini maka diharapkan dapat bermanfaat sebagai bahan informasi bagi pengusaha herbalife dalam memasarkan produknya secara efisien sehingga mereka mendapatkan keuntungan yang diinginkan.

\section{METODE PENELITIAN}

\section{Metode Penentuan Daerah Penelitian}

Penelitian ini dilakukan di Rumah Nutrisi Herbalife Green di Kota Manado Sulawesi Utara yang ditentukan seacara purposive dan dapat memberikan informasi penelitian dibutuhkan dalam penelitian. Penelitian ini dilakukan pada bulan Mei hingga Juli 2016.

\section{Metode Penelitian}

Metode yang digunakan dalam penelitian ini adalah metode studi kasus Rumah Nutrisi Green. Studi kasus adalah merupakan deskripsi mengenai suatu pengalaman dalam kehidupan nyata, berkaitan dengan bidang yang sedang dikaji atau dilatihkan, yang digunakan untuk menetapkan poin-poin penting, memunculkan masalah atau bahkan meningkatkan pemahaman dan pengalaman belajar dari para peserta. Pelaksanaannya biasanya mengikuti suatu skenario nyata, misalnya suatu masalah manajemen atau teknis, dari awal hingga akhir.Karena studi kasus memberikan contohcontoh nyata mengenai masalah-masalah dan solusi-solusi, tantangan- tantangan dan strategi-strategi.Studi kasus tersebut mendukung bahan-bahan yang lebih bersifat spesifik dan bahan informasi berdasarkan subjektif dan tidak dapat digeneralisir.Dan jumlah sampel yang diambil sebanyak satu yakni; pada rumah-rumah nutrisi yang ada di Manado.

\section{Metode Pengumpulan Data}

Data yang digunakan adalah data primer dan data sekunder. Data primer adalah diperoleh dengan melakukan wawancara langsung dengan member-member aktif herbalife

\section{Metode Analisis Data}

Untuk hipotesis a digunakan analisis deskriptif dan hipotesis b digunakan analisis SWOT berdasarkan bauran pemasaran dan strategi bisnis sebagai gambaran dan masukan dalam menentukan strategi pemasarannya dengan cara memanfaatkan kinerja manajer dari fungsi-fungsi kegiatan manajemen di suatu perusahaan, misalnya strategi operasional, strategi customer intimacy (keintiman dengan pelanggan), dan strategi keunggulan produk. Sehingga dapat menentukan kekuatan dan kelemahan didalam maupun peluang dan ancaman yang ada dimiliki suatu perusahaaan.Kemudian data yang diperoleh dimasukkan kedalam bentuk "matrik SWOT" yang terdiri dari strength, weakness, opportunies, andtreath. 
Menentukan suatu strategi pemasaran pada suatu usaha atau perusahaan, terlebih dahulu mengumpulkan data dan mengidentifikasi berbagai faktor eksternal (peluang dan Ancaman), dan faktor internal (kekuatan dan ancaman), dan faktor internal (kekuatan dan ancaman) yang ada pada perusahaan tersebut. Identifikasi dapat dilakukan dengan cara "Anlisis SWOT". Sehingga faktor eksternal dan internal dapat dianalisis yang akan menghasilkan sebuah strategi.

Cara membuat analisis SWOT melalui tiga tahapan yaitu: Tahap pengumpulan data, dimana tidak hanya sekedar kegiatan pengumpulan data dari beberapa faktor internal (kelemahan dan kekuatan) tetapi juga menganalisis data tersebut agar dapat diketahui nilai bobot ratingnya dengan menggunakan Matrik faktor strategi eksternal dan internal. Kemudian tahap analisis, dimana semua

Informasi yang berpengaruh terhadap kelangsungan perusahaan dapat digambarkan secara jelas, bagaimana peluang dan ancaman yang dihadapi perusahaan dapat disesuaikan dengan kekuatan dan kelemahan yang dilikinya, dan terakhir tahap pengambilan keputusan, dimana semua data yang telah dianalisis akan mengahasilkan beberapa alternatif untuk memperbaiki system pemasaran

\section{HASIL DAN PEMBAHASAN}

\section{Deskripsi Produk Herbalife di Kota Manado}

Herbalife berkembang di Kota Manado pada tahun 2001 dengan produk-produk yang ditawarkan oleh perusahan herbalife. Kemudian mencari member-member untuk mempromosikan produk-produk herbalife. Hingga sekarang herbalife sangat di kenal oleh masyarakat karena brand nya.

Kemudian perusahan herbalife dengan cara mempromosikan produk menarik sejumlah orang yang mau bekerja sama untuk perkembangan herbalife di kota Manado. Dengan sistem dan strategi perusahan yang ada. Di Kota Manado terdapat 2 independent distributor dan memiliki kurang lebih 100 mentor. Sedangkan terdapat 20 rumah nutrisi yang ada di seputaran kota Manado.
Rumah Nutrisi Herbalife Green ini berdiri pada bulan April tahun 2016 yang didirikan oleh seorang member yang sudah mengikuti sekolah Herbalife di Jakarta, karena itu merupakan salah satu syarat untuk membuka rumah nutrisi. Profil rumah nutrisi herbalife Green:

Nama Perusahan : Rumah Nutrisi Herbalife Green

Alamat Perusahan : Kompleks Mega Mas (D'Fitness)

Nama pemilik : Vera Bororing

Alamat Pemilik : Desa Sea Lingkungan 3

Tahun Berdiri ： 2016

\section{Sistem Pemasaran di Rumah Nutrisi Green}

Sistem pemasaran herbalife dilakukan di rumah nutrisi Green sebagai distibutor atau penyalur. Jadi konsumen dapat membeli langsung produk herbalife di rumah nutrisi Green dengan harga yang bervariasi di setiap level yang ada. Karena di setiap level mempunyai potongan diskon yang berbeda. Sedangakan di Rumah Nutrisi Green juga menyediakna produk yang siap di konsumsi dengan harga yang terjangkau yaitu Rp 270.000 per paket dan dapat di konsumsi selam 10 hari. Apabila konsumen mengambil paket tersebut, dari pihak Rumah Nutrisi Green ini memberikan bonus 1 buah masker herbalife.

Di rumah Nutrisi Green ini juga agenagen akan menawarkan kepada konsumen untuk menjadi member agar konsumen mendapatkan potongan diskon untuk pembelian produk, sehingga apabila sudah masuk dalam jaringan perusahan herbalife ini diharapkan membermember baru ini dapat merekrut lagi membermember yang lain agar dapat memperoleh keuntungan yang lebih besar dengan mengumpulkan poin dari hasil penjualan.

\section{Strategi Pemasaran Herbalife}

Mendirikan suatu usaha baik usaha kecil maupun besar, harus membuat perencanaan langkah awal, yaitu "strategi". Strategi sangat dibutuhkan karena mampu menghasilkan hasil yang positif dari apa yang telah direncanakan walaupun hasil yang didapat tidak begitu besar, serta didukung dengan kreatifitas para pelaku bisnis yaitu mampu memanfaatkan SDA dan penggunaanya tidak berlebihan dan juga pemerintah yang meminimalkan sistem birokrasi dalam mendirikan usaha (berbisnis) sehingga 
memudahkan para investor lokal asing untuk bekerjasama.

Dalam menentukan "strategi Pemasaran" suatu usaha atau perusahaan dapat dilakukan dengan cara yang telah dibahas pada halaman sebelumnya yaitu dengan menggunakan "Analisis SWOT" tetapi analisis SWOT kurang sempurna apabila tidak didukung dari bebarapa teori yang ada pada "strategi Bisnis"

Berdasarkan peninjauan langsung ke lapangan (Rumah Nutrisi Herbalife) sesuai dengan beberapa metode yang digunakan. Tahap yang pertama adalah "tahap pengumpulan data". Maka, dapat diketahui yang menjadi kekuatan, kelemahan, peluang, dan ancaman yang ada pada Rumah Nutrisi Herbalife, yaitu;

1. Beberapa kelemahan pada Rumah Nutrisi Herbalife :
a. Tidak ada hubungan kerjasama denganinvestor.
b. Kurang pengalaman dalamberbisnis.
c. Ruangan yang kurang memadai.
d. Kurangnya tenaga kerja.
e. Kurangnya promosi

2. Beberapa kekuatan yang dimiliki Rumah
Nutrisi Herbalife :

a. Lokasi yang cukup strategis,yang berada di kawasan mega mas (D'Fitness)

b. Keunggulan Produk

c. Mimiliki Pelanggan Tetap

d. Memiliki cabang diKalasey.

e. Bersikap jujur dan ramah terhadap pelanggan.

3. Beberapa peluang yang kemungkinan terjadi pada Rumah Nutrisi Herbalife:

a. Kemungkinan menguasai pasar di Sulawesi Utara.

b. Kemungkinan dapat memiliki jaringan atau agen lebih banyak.

c. Kemungkinan para investor bermunculan.

d. Kemungkinan memiliki banyak cabang di wilayahSulawesi Utara.

4. Beberapa ancaman yang dihadapi Rumah Nutrisi Herbalife:
a. Ketidaksadaran masyarakat akan kesehatan.
b. Bertambahnya usaha yangsejenis.
c. Adanya pemungutan illegal
d. Daya beli konsumen menurun.

Tabel 2. Matrik Faktor Strategi Internal Rumah Nutrisi Herbalife

\begin{tabular}{|l|c|c|c|}
\hline \multicolumn{1}{|l|}{ Faktor-faktor Strategi internal } & Rating & Bobot & $\begin{array}{c}\text { Skor } \\
\text { Pembobotan }\end{array}$ \\
\hline $\begin{array}{l}\text { Kekuatan: } \\
\text { - Lokasi yang cukup strategis. }\end{array}$ & 3 & 0.2 & 0.6 \\
- Keunggulanproduk. & 4 & 0.27 & 1.08 \\
- Memiliki pelanggan tetap. & 2 & 0.13 & 0.26 \\
- Memiliki cabang di Kalasey. & 2 & 0.13 & 0.26 \\
- Bersikap jujur dan ramah terhadap & 4 & 0.27 & 1.08 \\
$\quad$ pelanggan. & & & $\mathbf{3 . 2 8}$ \\
\hline Jumlah: & $\mathbf{1 5}$ & $\mathbf{1 . 0}$ & 0.5 \\
\hline $\begin{array}{l}\text { Kelemahan: } \\
\text { Tidak ada hubungan kerjasama dengan } \\
\text { investor. }\end{array}$ & 2 & 0.25 & 0.5 \\
Kurang pengalaman dalam berbisnis. & 2 & 0.25 & 0.5 \\
- Ruangan yang kurang memadai. & 2 & 0.25 & 0.125 \\
- Kurangnya tenaga kerja & 1 & 0.125 & 0.125 \\
\hline Kurangnya promosi & 1 & 0.125 & $\mathbf{1 . 7 5}$ \\
\hline Jumlah: & $\mathbf{8}$ & $\mathbf{1 . 0}$ & \\
\hline
\end{tabular}


Tabel 3. Matrik Faktor Strategi Eksternal Rumah Nutrisi Herbalife

\begin{tabular}{|c|c|c|c|}
\hline Faktor-faktor Strategi Eksternal & Rating & Bobot & $\begin{array}{l}\text { Skor Pembobotan } \\
\text { (Rating x bobot ) }\end{array}$ \\
\hline $\begin{array}{l}\text { Peluang: } \\
\text { - Kemungkinan menguasai pasar di } \\
\text { Sulawesi Utara } \\
\text { - Kemungkinan memiliki } \\
\text { jaringan atau agen lebih } \\
\text { banyak. } \\
\text { - Kemungkinan para } \\
\text { investor berdatangan } \\
\text { - Kemungkinan memiliki banyak } \\
\text { cabang di Sulawesi Utara. }\end{array}$ & $\begin{array}{l}2 \\
3\end{array}$ & $\begin{array}{l}0,25 \\
0.34 \\
0.16 \\
0,25\end{array}$ & $\begin{array}{l}0,75 \\
1,36 \\
0,32 \\
0,75\end{array}$ \\
\hline Jumlah & 12 & 1.0 & 3,18 \\
\hline $\begin{array}{l}\text { Ancaman: } \\
\text { - } \quad \text { Ketidaksadaran masyarakat } \\
\text { terhadap kesehatan } \\
\text { - } \quad \text { Bertambahnya usaha yang sejenis. } \\
\text { - } \text { Adanya pemungutan ilegal. } \\
\text { - Daya beli konsumen menurun. }\end{array}$ & $\begin{array}{l}2 \\
1 \\
2\end{array}$ & $\begin{array}{l}0,37 \\
0,25 \\
0,13 \\
0,25\end{array}$ & $\begin{array}{c}1,11 \\
0,5 \\
0,13 \\
0,5\end{array}$ \\
\hline Jumlah & 8 & 1.0 & 2,24 \\
\hline
\end{tabular}

Dari Tabel 2 dan 3 dapat dijelaskan bahwa:

1. Jumlah dari skor pembobotan pada peluang yaitu 3,18 masih dibawah nilai dari kekuatan yaitu 3,28. Sehingga dapat menciptakan strategi yang menggunakan kekuatan untuk memperoleh peluang, hal ini ditandai dengan adanya keunggulan produk dan pelayanan yang baik terhadap pelanggan, sehingga dapat memperoleh peluang yang menguasai pasarmonopolistik.

2 Jumlah dari skor pembobotan pada kekuatan lebih besar yaitu 3,28 dibandingkan skor pembobotan pada ancaman yaitu 2,24. Sehingga dapat menciptakan strategi yang menggunakan kekuatan untuk mengatasi ancaman seperti ketidaksadaran masyarakat terhadap kesehatan dan menurunnya daya beli kosumen dapat di atasai dengan mempromosikan produk terhadap masyarakat luas.

3. Jumlah dari skor pembobotan pada kelemahan lebih rendah yaitu 1,75 dibandingkan skor pembobotan pada peluang yaitu 3,18 . Sehinggadapat menciptakan strategi pada peluang yang mampu meminimalkan kelemahan, yang ditandai lemahnya Rumah Nutrisi Herbalife yang kurang di promosikan terhadap masyarakat luas. Hal ini dapat diantisipasi dengan menggunakan sistem penjualan door to door (rumah ke rumah) atau penggunaan iklandan membuat kas perusahaan Rumah Nutrisi Herbalife mempunyai dana cadangan untuk menutupi biaya di bulan/tahun berikutnya yang disebabkan hasil keuntungan yang menurun.

4. Jumlah dari skor pembobotan pada kelemahan lebih rendah yaitu 1,75dibandingkan skor pembobotan pada ancaman yaitu 2,24. Sehingga, ancaman dapat diminimalkan karena nilai bobot pada kelemahan lebih rendah. Tetapi kedua faktor tersebut tetap harus dihindari, dengan menggunakan strategi yang bersifat defensif yang artinya suatu usaha atau perusahaan tersebut harus bertahan khususnya mengenai urusan keuangan, 
dengan cara harus mengurangi biaya, mencari pinjaman dana (Bank) atau menjalin hubungan kerjasama denganinvestor.

Penjelasan hasil diatas dari tahap pengumpulan data, dapat diperoleh lagi yang lebih spesifik, dengan membuat "tahap analisis“, dimana memanfaatkan semua informasi kedalam model perumusan strategi. Model tersebut adalah Matrik SWOT, sehingga beberapa kategori yang muncul yakni strategi SO, strategi ST, strategi WO, dan strategi WT dapat diperoleh Tabel 4.

\section{Tabel 4. Bentuk Matrik SWOT}

\begin{tabular}{|c|c|c|}
\hline INTERNAL & STRENGTHS (S) & WEAKNESSES (W) \\
\hline EKSTERNAL & $\begin{array}{ll}\text { - } & \text { Lokasi yang cukup } \\
& \text { strategis. } \\
\text { - } & \text { Keunggulan produk. } \\
\text { - } & \text { Memiliki pelanggan } \\
\text { tetap. } & \\
\text { - } & \text { Memiliki cabang di } \\
\text { Kalasey. } & \\
\text { - } & \text { Bersikap jujur dan } \\
\text { ramah } & \text { terhadap } \\
\text { pelanggan }\end{array}$ & $\begin{array}{l}\text { Tidak ada hubungan } \\
\text { kerjasama dengan } \\
\text { investor. } \\
\text { Kurang pengalaman } \\
\text { dalam berbisnis. } \\
\text { Ruangan yang kurang } \\
\text { memadai. } \\
\text { Kurangnya tenaga kerja } \\
\text { Kurangnya promosi }\end{array}$ \\
\hline $\begin{array}{l}\text { OPPORTUNIES }(\mathrm{O}) \\
\text { - } \text { Kemungkinan menguasai } \\
\text { pasar di Sulawesi Utara } \\
\text { - } \text { Kemungkinan } \\
\text { memiliki jaringan } \\
\text { atau agen lebih } \\
\text { banyak. } \\
\text { - Kemungkinan para } \\
\text { investor } \\
\text { berdatangan } \\
\text { Kemungkinan memiliki } \\
\text { banyak cabang di Sulawesi } \\
\text { Utara. } \\
\end{array}$ & \begin{tabular}{l}
\multicolumn{2}{c}{ STRATEGI SO } \\
1. Mengandalkan \\
keunggulan produk \\
serta tetap menjaga \\
palayanan yang sebaik \\
mungkin terhadap \\
konsumen. \\
2. Memperluas jaringan \\
pasar ke wilayah di \\
Sulawesi Utara.
\end{tabular} & $\begin{array}{l}\text { STRATEGI WO } \\
\text { 1. Menggunakan sistem } \\
\text { penjualan door to } \\
\text { door(rumah ke rumah) atau } \\
\text { penggunaan iklan. }\end{array}$ \\
\hline 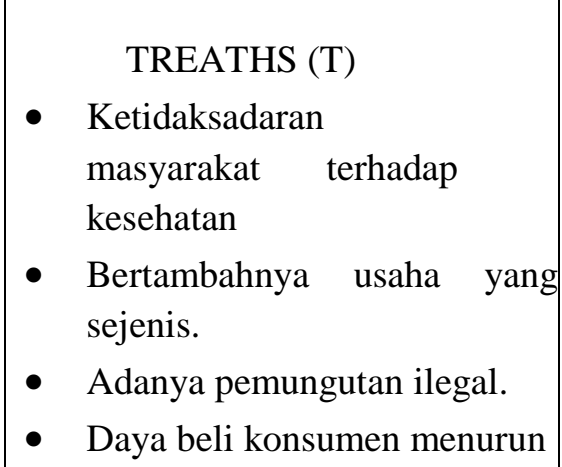 & $\begin{array}{l}\text { STRATEGI ST } \\
\text { 1. Kembangkan saluran } \\
\text { keseluruh wilayah di } \\
\text { Sulawesi Utara. } \\
\text { 2. } \begin{array}{l}\text { Merger dengan usaha } \\
\text { yang sejenis. }\end{array}\end{array}$ & \begin{tabular}{l}
\multicolumn{3}{c}{ STRATEGI WT } \\
1. Mengurangi biaya lain- \\
lain. \\
2. Mencari pinjaman \\
dana (Bank) atau \\
menjalin \\
kerjasama hubungan \\
investor. dengan
\end{tabular} \\
\hline
\end{tabular}


Tahap terakhir yaitu "tahap pengambilan keputusan" yang bertujuan untuk menyusun beberapa strategi yang telah digambarkan oleh Matrik SWOT, sehingga strategi yang muncul dapat dijadikan sebagai acuan dalam memperbaiki pemasaran pada Rumah Nutrisi Herbalife. Adapun strategi yang dimaksud adalah:

1. Mengandalkan keunggulan produk serta tetap menjaga palayananyang sebaik mungkin terhadap konsumen

2. Memperluas jaringan pasar keluar daerah, agar Herbalife semakin dikenal dan semakin besar keuntungan dari penjualan serta dari penggunaan branding Herbalife.

3. Kembangkan saluran dengan bekerjasama dengan investor lain agar dapat berkembang dengan membuka cabang dimana-mana.

4. Merger dengan usaha yang sejenis, dimana mencari kekuatan baru dengan menggabungkan usaha yang sejenis baik

5. dalam bentuk kerjasama jalur pemasarannya maupun dalam bentuk penggabungan modal.

6. Menggunakan sistem penjualan door to door (rumah ke rumah) atau penggunaan iklan di sekitar lokasi usaha (Kawasan MegaMas) sebagai informasi, sehingga memudahkan konsumen lainnya untuk mencari Rumah Nutrisi Herbalife.

7. Mengurangi biaya lain-lain

8. Mencari pinjaman dana (Bank) atau menjalin hubungan kerjasama dengan investor.

\section{KESIMPULAN DAN SARAN}

\section{Kesimpulan}

1. Kekuatan yang dapat diandalkan Rumah Nutrisi Herbalife yaitu keunggulan produk dan sikap jujur, ramah terhadap pelanggan.

2. Kelemahan yang dimiliki Rumah Nutrisi
Herbalife yaitu; pertama, kurangnya pengalaman berbisnis sehingga sulit dalam mengelola keuangan, sehingga perusahaan dapat mengalami krisis keuangan (menurun) apabila perusahaan tersebut terkena dampak dari perekonomian dunia yang sedang drop atau jatuh dan kedua, tidak menggunakan jasa promosi atau iklan baik visual maupun nonvisual.

3. Peluang terbesar yang mungkin dapat diperoleh Rumah Nutrisi Herbalife yaitu dapat menciptakan pasar monopolistik.

4. Ancaman terbesar yang dihadapi Rumah Nutrisi Herbalife yaitu daya beli konsumen menurun dan ketidaksadaran masyarakat terhadap kesehatan, dan harga yang lumayan mahal.

\section{Saran}

1. Untuk mengatasi kelemahan pada Rumah Nutrisi Herbalife yaitu disarankan membuat kas perusahaan dan menjalin hubungan kerjasama dengan pihak investor, sehingga Rumah Nutrisi Herbalife mempunyai uang cadangan untuk menutupi biaya produksi dibulan atau ditahun yang akan datang apabila terjadi krisis perekonomian dunia serta pengunaan iklan non-visual di kawasan Mega Mas yang berisikan alamat/lokasi, sehingga menambah informasi bagi konsumen lainnya

2. Untuk meminimalkan ancaman yang dihadapi Rumah Nutrisi Herbalife yaitu disarankan Rumah Nutrisi herbalife mengembangkan saluran pemasarannya dan membuka cabang diberbagai tempat (kota) di wilayah Sulawesi Utara, sehingga memperluas jaringan penjualan.

3. Disarankan kepada Rumah Nutrisi untuk tetap mempertahankan strategi yang telah diterapkan dan menambah strategi pemasarannya yaitu "strategi investasi", dimana strategi ini lebih mengutamakan perkembangan usaha yang lebih besar 


\section{DAFTAR PUSTAKA}

Keller, Kevin Lane, 2007, Manajemen Pemasaran, indeks, Jakarta.

Kotler, Phillip., 2000, Manajemen Pemasaran, Erlangga, Jakarta.

Kotler, Philip., 2007, Manajemen Pemasaran,Edisi 12, Erlangga, Jakarta.

Laksana, Fajar., 2008, Manajemen Pemasaran, Edisi Pertama, Graha Ilmu, Yogyakarta.

Lamb, Charles, W., 2001, Pemasaran, Salemba Empat, Jakarta.
Radiosuno, 1987, Konsep, Sistem, dan Fungsi Manajemen Pemasaran, FE- UGM, Yogyakarta.

Rangkuti, Freddy., 1997, Analisis SWOT, Teknik Membedah Kasus Bisnis, Gramedia Pustaka Umum, Jakarta.

Sumarni, Murti dan John Soeprihanto. 2010. Pengantar Bisnis (Dasar-dasar Ekonomi Perusahaan). Edisi ke 5. Yogyakarta: Liberty Yogyakarta

Tjiptono, Fandy. 2008. Strategi Pemasaran. Edisi ke 3. Yogyakarta: Andi 